\title{
Debate sobre culturas alimentares: conversas em torno da cultura alimentar brasileira
}

\section{Debate sobre cultivos alimentarios: conversaciones en torno a la cultura}

\author{
alimentaria brasileña
}

Debate on food cultures: talks about Brazilian food culture

\author{
Antonio Carlos Barbosa da Silva ${ }^{1}$ \\ Marina Coimbra Casadei Barbosa da Silva²
}

\begin{abstract}
Resumo
O presente artigo apresenta uma atividade em educação alimentar e nutricional (EAN) no campo das políticas públicas de alimentação brasileira e foi desenvolvida em uma escola pública. A intervenção foi promovida pela PROGRAD - Núcleo de Ensino da Unesp de Assis e pelo Ministério do Desenvolvimento Social e Combate à Fome/CNPq/Sesan - Processo 407514/2012-0. A preocupação do trabalho foi salvaguardar a cultura e história que adorna a alimentação brasileira e apresentá-la aos estudantes de ensino médio de uma escola pública como elemento constituinte da identidade cultural e social do Brasil. Através de respaldos da educação crítica e da psicologia histórico-cultural e sócio-histórico subsidiou-se rodas de conversa e oficinas de culinária a respeito da alimentação brasileira junto a três grupos abertos de alunos entre nove e treze anos. $\mathrm{O}$ trabalho demonstrou que educação alimentar e nutricional é uma ação que pode prover: a saúde nutricional da população; possibilitar a reflexão sobre o comportamento alimentar, que atualmente é moldado pela indústria alimentar; valorizar as tradições alimentares; diminuir a preferência por alimentos ultraprocessados, calóricos, energéticos e prejudiciais à saúde.
\end{abstract}

Palavras-chave: Alimentos ultraprocessados; cultura; educação alimentar e nutricional.

\section{Resumen}

El presente artículo presenta una actividaden educación alimentaria y nutricional (EAN) e nel campo de las políticas públicas de alimentación brasileña y fue desarrollada en una escuela pública. La intervención fue promovida por la PROGRAD - Núcleo de Enseñanza de la Unesp de Asís y por El Ministerio de Desarrollo Social y Combate al Hambre / CNPq / Sesan - Proceso 407514 / 2012-0. La preocupación Del trabajo fue salvaguardar la cultura e historia que adorna La alimentación brasileña y presentar la a los estudiantes de enseñanza media de una escuela pública como elemento constituyente de La identidad cultural y social de Brasil. Através de respaldos de La educación crítica y de La psicología histórico-cultural y socio-histórico se subsidió ruedas de conversación y talleres de culinária respecto a La alimentación brasileña junto a tres grupos abiertos de alumnos entre nueve y trece años. El trabajo demostró que La educación alimentaria y nutricional es una acción que puede prove er: La salud nutricional de La población; que permita La reflexión sobre El comportamiento alimentario, que actualmente es moldeado por La industria alimentaria; valorizar lãs tradiciones alimentarias; disminuir La preferencia por alimentos ultraprocesados, calóricos, energéticos y perjudiciales para La salud.

Palabras clave: Alimentos ultraprocesados; la cultura; educación alimentaria y nutricional.

\footnotetext{
${ }^{1}$ Doutor em Psicologia pela PUC-Campinas, Professor RDIDP do Departamento de Psicologia Social e Educacional da Unesp-Assis. antonio.cb.silva@unesp.br

${ }^{2}$ Doutoranda em Educação pela Programa de Pós-Graduação Unesp-Marília, Bolsista

CAPES.graunasilva@gmail.com
} 


\begin{abstract}
This article presents an activity in food and nutritional education (EAN) in the field of Brazilian public food policies and was developed in a public school. The intervention was promoted by PROGRAD - Teaching Nucleus of Unesp of Assis and by the Ministry of Social Development and Fight against Hunger / CNPq / Sesan - Case 407514 / 2012-0. The concern of the work was to safeguard the culture and history that adorns the Brazilian food and present it to the high school students of a public school as a constituent element of the cultural and social identity of Brazil. Through support from critical education and historical-cultural and sociohistorical psychology, talk wheels and cooking workshops were subsidized in relation to Brazilian food, along with three open groups of students between nine and thirteen years old. The study demonstrated that food and nutritional education is an action that can provide: the nutritional health of the population; to enable reflection on food behavior, which is currently shaped by the food industry; valuing food traditions; to reduce the preference for ultraprocessed, caloric, energy and harmful foods.
\end{abstract}

Keywords: Ultraprocessed foods; culture; food and nutrition education.

\title{
1. Introdução
}

As políticas nacionais de alimentação e nutrição (PNAN) existem no Brasil desde 1930 e se transformaram ao longo de seus 86 anos de existência. De uma política inicial voltada para equacionar as dificuldades na distribuição de alimentos em um país com dimensões continentais tornou-se na última década em uma política que defende o respeito, a proteção, a promoção e o provimento dos direitos humanos à saúde e à alimentação junto à população brasileira. (BELIK, 2001).

As PNAN da última década se preocupam com o aumento de várias doenças crônicas degenerativas que estaria relacionado aos hábitos alimentares da população, principalmente aqueles relacionados ao consumo excessivo de alimentos industrializados e ultraprocessados.

Na edição de 2013, a PNAN reafirmou como propósito a melhoria das condições de alimentação, nutrição e saúde da população brasileira.

Para que essas práticas fossem desenvolvidas, a educação alimentação e nutricional (EAN) foi uma estratégia a ser defendida e postulada, principalmente, junto a estudantes de escolas públicas. A EAN incentiva a criação de ambientes institucionais promotores de alimentação adequada e saudável, que fazem parte da cultura alimentar brasileira, incidindo sobre a oferta de alimentos saudáveis nas escolas e nos ambientes domésticos. (ALVES; JAIME, 2014)

A PNAN de 2013, ao apontar a EAN como estratégia para favorecer a consciência sobre a cultura alimentar e, conseqüentemente, melhorar a saúde nutricional dos brasileiros, também atribui aos educadores de diversos setores a responsabilidade em orientar as crianças de forma crítica sobre o ato de alimentar-se a partir dos diversos sistemas culturais, local, regional e nacional. 
Portanto, a EAN é um dos caminhos existentes para a promoção da saúde, que leva a população a refletir sobre o seu comportamento alimentar a partir da conscientização sobre a importância da alimentação para a saúde, permitindo a transformação e o resgate dos hábitos alimentares tradicionais.

De certa forma, quem trabalha em EAN, além de associá-la a uma educação para a saúde, deve focar suas questões educativas de forma crítica e transformadora. Para Boog (1997) um trabalho viável e crítico na promoção da EAN valorizam e resgatam elementos da cultura alimentar, respeitando e modificando crenças e atitudes em relação à alimentação. Outros componentes pertencentes ao contexto cultural, social, econômico e ecológico que envolva a alimentação devem ser também analisados, fazendo com que crenças e valores da população em relação à nutrição sejam refletidos e aprofundados.

\section{Cultura alimentar brasileira}

A cultura alimentar brasileira engloba a cultura original de populações nativas, assim como um vasto número de tradições, como a africana, portuguesa, espanhola, alemã, francesa, holandesa entre outras. Muitos alimentos típicos brasileiros são bem conhecidos, como por exemplo, açaí, guaraná, mangaba, mandioca, castanha do Pará. No entanto, existem muitos outros alimentos nutritivos e saborosos originais ou introduzidos há longas datas (aves, caprinos, arroz vermelho, amêndoas de cocos etc.) que eram apreciados e faziam parte das refeições familiares, mas que foram, aos poucos, esquecidos ou desvalorizados. Entre as principais razões do abandono gradual desses alimentos está o fato de as pessoas migrarem para as cidades grandes, viverem sob a égide de uma sociedade que valoriza a celeridade e dispõe de menos tempo para se dedicar a arte da cozinha, além do consumo excessivo de alimentos industrializados, disfuncionais e calóricos, os quais dão rápida saciedade e têm baixo custo. Dessa forma, o acesso aos alimentos, na sociedade moderna, predominantemente urbana, é determinado pela estrutura socioeconômica e pelo estilo de vida célere, individual e consumista da sociedade contemporânea.

Segundo Garcia (2003), a uniformização de certas práticas e do comportamento alimentar facilitou as mudanças na alimentação que tem sido cada dia mais incorporado como parte do modo de vida operante. Pressionadas pelo poderio aquisitivo, pela publicidade e praticidade, as práticas alimentares se tornaram permeáveis às mudanças, representadas pela incorporação de novos alimentos, formas de compra, preparo e consumo, sendo que atualmente há vasta gama de comidas que necessitam apenas serem descongeladas, as 
comidas do tipo fastfood, e os ultraprocessados. Contudo, é possível que haja resistência por parte das pessoas em aderirem esse tipo de padrão alimentar se realizarmos ações educativas da cultura alimentar, da consolidação das boas práticas alimentares e valorização do símbolo dos alimentos e comidas nacionais.

Para Dória (2002) a culinária brasileira, composta pelas culturas indígenas e pela herança negra e ocidental ibérica, são por analogia, três línguas diferentes, três sistemas culinários irredutíveis uns aos outros que, apesar de estar presente no repertório culinário brasileiro nos últimos 500 anos, ainda não foi totalmente incorporado à identidade da sociedade.

Talvez isso ocorra pela falta de interesse das elites dominantes, cujos olhares sempre se voltaram para a Europa e, mais recentemente, para os Estados Unidos, em uma perspectiva de imitação, reservando desprezo por aquilo que é nativo. (DÓRIA, 2002)

Este suposto caráter permeável da cultura resultaria em uma capacidade de importar novas práticas e gostos, de gerar novas demandas, de assumir prontamente mudanças no modo de vida e de abandonar aqueles costumes e práticas que conformam uma identidade própria. Sejam quais forem às explicações para as mudanças sofridas nas práticas alimentares, é certo que elas engendram um novo padrão alimentar. No mesmo sentido, observa-se que as novas políticas públicas de alimentação no Brasil evidenciam essa preocupante questão:

\footnotetext{
"É mais do que à hora de resgatar os usos destes alimentos ricos em vitaminas e minerais para reverter quadros clínicos de deficiências nutricionais, diminuindo o risco de infecções, principalmente em crianças. Assim, conhecendo os alimentos de sua região e sabendo os que são seguros e que contém boas fontes de nutrientes o sujeito se capacita a escolher de forma mais consciente a comida. $\mathrm{O}$ conhecimento, a valorização, a produção e a utilização dos alimentos regionais na comunidade encoraja o orgulho e a auto-suficiência da mesma, colaborando para a melhoria da economia local e da qualidade de vida." (BRASIL, 2002, P. 10).
}

Para Rodrigues (2012), as crianças, que por ser uma camada da população mais frágil diante do estilo de vida consumista da contemporaneidade e das artimanhas sedutoras da indústria alimentícia e marqueteira são as que mais têm seus hábitos alimentares padronizados pelo consumo excessivo de alimentos ultraprocessados.

Esses hábitos são contaminados por produtos menos nutritivos (guloseimas e salgadinhos em pacotes) já que eles estão cada vez mais baratos, sempre disponíveis nas prateleiras dos supermercados, são altamente palatáveis, atrativos na apresentação e potencializados pelo grande número de propagandas televisivas que os cercam. 
Além disso, o fortalecimento de uma alimentação com base em alimentos ultraprocessados ou industrializados aniquila qualquer possibilidade da criança vir a ter contato mais profundo com a história de sua cultura alimentar, impossibilitando-a em participar de um processo cultural que envolve aprendizagens e transformações cognitivas e sociais (o simples ato de cozinhar envolve diversos saberes - escolhas, tempo de cozedura, combinações de alimentos, limpeza etc. - e encontros dialógicos - discussão sobre origem dos alimentos, receitas, troca de informações etc.). Sem esse tipo de vivência a criança fica à mercê das imposições da sociedade consumista.

\footnotetext{
"Na era contemporânea a comida parece sofrer as imposições de um campo de força que tem no modelo da globalização e do neoliberalismo seus exemplos. Assim, o alimento que pode ser reproduzido exatamente em formato, sabor, textura e cor nas mais diferentes e longínquas regiões do planeta, o alimento feito do modo mais rápido, que proporciona prazer e adequação nutricional serão os mais valorizados. Portanto, no mundo atual, marcado pela velocidade, pela produção excessiva e sobressalente de produtos, não valoriza os rituais que envolvem o ato de comer. A falta de tempo do mundo contemporâneo levou o sistema neoliberal desenvolver todo um mercado de alimentos semi-prontos, congelados, práticos, individualizantes etc." (SILVA, 2015, p. 250)
}

Para Valente (2002), a retomada dos processos históricos e sociais que estão por trás da nutrição e o possível fortalecimento dos movimentos educativos populares na reivindicação de uma alimentação mais consciente e saudável, deixam as ações em EAN mais críticas em relação à fluidez incessante que domina a sociedade contemporânea e capacita o sujeito a planejar um estilo de vida a partir de uma alimentação mais saudável.

Michael Pollan (2014), jornalista e ativista político e ecológico, defende que talvez a única forma do sujeito contemporâneo enfrentar a indústria alimentar e seus malefícios sejam resgatando antigos hábitos alimentares culturais que evidenciam o preparo caseiro da comida e quando possível.

As propostas das ações em EAN que contam com os princípios de uma educação crítica possibilitam ao sujeito encontrar condições para descobrir-se e conquistar-se em sua própria história e ser capaz de sozinho controlar seus problemas, após o diálogo com os educadores.

A educação crítica deve transformar a dependência dos sujeitos sobre os educadores em independência, com reflexão e ação, através da conscientização dos mesmos. É preciso que os sujeitos tomem consciência de sua realidade para depois transformá-la. Vale à pena, então, pensar a condição atual do sistema alimentar operante, debatê-lo, redefini-lo e desenvolver novas formas de estabelecer uma alimentação saudável, histórica e cultural. 
A educação crítica implica em um constante esclarecimento da realidade, resultando na inserção reflexiva na realidade dos sujeitos e na negação do homem abstrato, isolado, desligado do mundo. Essa educação visa a construção de um sujeito ativo e interativo.

\begin{abstract}
“(...) esse processo não é um determinismo histórico e cultural em que, passivamente, o sujeito absorve determinados comportamentos para reproduzi-los, posteriormente. Ele deve participar ativamente da construção de sua própria cultura e de sua história, modificando-se e provocando transformações nos demais sujeitos que com ele interagem. A prática alimentar é um elemento histórico-cultural, que ultrapassa o sentido de nutrir-se para sobreviver. Ela está relacionada aos aspectos pessoais, subjetivos, familiares e históricos presentes na preparação e no consumo dos alimentos. (BARBOSA DA SILVA, p.20, 2016)
\end{abstract}

A descrição que se apresenta a seguir diz respeito às práticas educativas em EAN junto a crianças de uma escola pública da cidade de Assis em São Paulo. As práticas desenvolvem o diálogo e a reflexão com crianças. As ações centram-se na adoção de hábitos alimentares saudáveis, críticos e culturais com a intenção de possibilitar um encontro criativo com a história da alimentação, além de municiar as crianças com informações a respeito da composição física e subjetiva dos alimentos ultraprocessados.

Os objetivos gerais que nortearam as ações foram: pensar nos elementos culturais que configuram a comida brasileira; refletir sobre a importância da alimentação saudável e nutricionalmente adequada; criticar a alimentação baseada em alimentos ultraprocessados; e esclarecer as possíveis doenças que podem desenvolver a partir do consumo excessivo de alimentos disfuncionais (junkfood).

\title{
3. Metodologia
}

O trabalho foi estruturado metodologicamente de forma a construir espaços dialógicos de reflexão na escola no qual poderiam ser realizadas as ações em EAN. Esses espaços aguçaram nos alunos indagações e reformulações a respeito dos processos que levam os sujeitos a consumirem sem crítica alimentos industrializados que alem de atentarem contra a saúde afastam os afasta da cultura alimentar de seu país. Nesses espaços a técnica das rodas de conversa foi utilizada.

Nesses tipos de ações participativas foram priorizado discussões em torno da temática alimentar e, no processo dialógico, os sujeitos apresentam suas elaborações a respeito da alimentação, mesmo contraditórias, sendo que cada pessoa instigou a outra a falar, sendo possível se posicionar e ouvir o posicionamento do outro. Esse diálogo compartilhado permitiu que as histórias dos sujeitos em relação às práticas alimentares fossem re- 
significados. Para auxiliá-las nesse processo as chamadas intervenções grupais em psicologia foram utilizadas (discussões coordenadas pela equipe com grupos de alunos do ensino médio) com respaldos teóricos das psicologias críticas (histórico-cultural, sócio histórico e psicologia social crítica) e práticos (dinâmicas e oficinas de culinárias que levaram os participantes a refletir sobre as demandas em torno da alimentação brasileira).

Durante o ano letivo de 2015 desenvolveu-se atividades de EAN com três grupos abertos com cerca de dez a vinte alunos cada com idade entre nove a treze anos de uma escola pública de Assis-SP. As intervenções ocorrem a cada quinze dias. Foram desenvolvidas cerca de dez intervenções. As oficinas foram divididas em rodas de conversas sobre as práticas alimentares contemporâneas; em rodas de conversas sobre a cultura alimentar tradicional brasileira; e em oficinas práticas reflexivas sobre o preparo de comidas brasileiras típicas. Como eram grupos abertos um mesmo estudante participava de uma ou mais oficina. A oficina de culinária, entretanto, contava com cerca de 20 participantes, pois tinha como atrativo a degustação das comidas que eram preparadas durante a mesma.

O projeto para ser desenvolvido na escola teve a autorização da direção da Escola e dos pais dos participantes.

A equipe que desenvolveu as atividades (rodas de conversas e culinária) contou com o coordenador do projeto (professor de Psicologia), uma pesquisadora em Educação (bolsista CNPq/MDS/Sesan), quatro alunos de Psicologia, sendo dois bolsistas da Prograd e dois bolsistas da CNPq/MDS/Sesan e um estagiário de Nutrição (bolsista CNPq/MDS/Sesan).

4.

Resultados e Discussões

As oficinas tiveram a intenção de estabelecer uma EAN que através do debate informasse e conscientizasse os sujeitos a respeito dos elementos históricos, nutritivos, ideológicos, econômicos que podem estar por trás das práticas alimentares que fazem parte da cultura brasileira.

O grupo desenvolveu as atividades a cada quinze dias nas salas de aula, no pátio ou na cozinha da escola.

\subsection{Rodas de conversas - práticas alimentares contemporâneas}

Nessa oficina, as discussões centraram-se em analisar os alimentos industrializados e como eles fazem parte do cotidiano alimentar da população. Segundo dados do Instituto Brasileiro de Geografia e Estatística (IBGE) de 2014 o consumo de alimentos industrializados 
representou cerca de $85 \%$ do consumo brasileiro contra apenas $15 \%$ dos produtos in natura. Pode-se afirmar que a indústria alimentar tem um papel relevante sobre a prática alimentar atual do brasileiro.

O grupo estudou e debateu a composição de alguns alimentos industrializados (biscoitos, doces achocolatados, salgadinhos em pacote à base de milho e batatas fritas empacotadas) com enfoque para a quantidade de açúcares, gorduras, sais e aditivos químicos que há nesses alimentos. Além, de investigar os possíveis malefícios que uma dieta com excesso desses alimentos causa ao organismo das pessoas.

Esses debates reforçaram o diálogo em torno dos ingredientes que estão mascarados em diversos alimentos industrializados. Sob nomes científicos, de difícil compreensão para a maioria da população, esses ingredientes escondem a quantidade de açucares que há nos alimentos industrializados. Sob o nome demaltodextrina, frutose, dextrose, xilose, néctar, maltose, xarope de milho etc. tentam escondem sua real descrição - glicose. A quantidade de sal também é mascarada a partir da nomenclatura cloreto de sódio, conservantes. As gorduras trans são mascaradas pelas nomenclaturas gorduras vegetais hidrogenadas.

Para incrementar o debate utilizaram-se como recursos diversos recortes de documentários que debatem tais questões (Além do Peso, Comida S.A., FedUp, SuperSize $M e$ ). Esse tipo de ação é de estrema importância, pois há poucas campanhas educativas governamentais que informam corretamente os ingredientes que há nos alimentos ultraprocessados.

Em outro debate proveniente desse tipo de atividade analisou-se a composição dos sucos em embalagens de longa duração. A maioria desses sucos não apresenta nenhum ingrediente in natura, apesar da descrição em sua embalagem mascarar seus reais ingredientes dando a impressão de que há um suco natural nesse produto.

Outro assunto abordado foi como o organismo reage diante do consumo excessivo de produtos ultraprocessados à base de açúcar. Para ilustrar esse debate apresentou-se um episódio do seriado televisivo animado mundialmente conhecido Simpson (animação que está na programação da TV desde 1989), foi apresentado e trabalhado junto ao grupo. No episódio o personagem Bart fica dependente de açúcar ao comer excessivamente produtos industrializados. O enredo do desenho é crítico ao assinalar os efeitos negativos do excesso de açúcar no organismo. Os debates que se seguiram com essa atividade destacaram o descontrole que envolve o consumo excessivo de alguns ingredientes enérgicos e como esses são ocultados e mascarados nos rótulos dos alimentos industrializados. Como se abordou anteriormente a indústria alimentícia tem como estratégia dificultar a compreensão do 
consumidor a respeito dos verdadeiros ingredientes que há em seus produtos. Avaliza-se que se o sujeito tem clareza sobre o que poderá consumir tenderá a fazer uma escolha mais consciente.

Aqui vale a pena apontar que em uma sociedade célere, tecnológica, o tempo para comprar, encontrar alimentos in natura se torna uma tarefa árdua. Dentre os alimentos de um supermercado $90 \%$ contém algum aditivo químico e a maioria é feito à base de farináceos refinados a base de soja, trigo e milho. (CARREIRO, 2014)

\section{2. $\quad$ Rodas de conversas - cultura alimentar tradicional brasileira}

Essas oficinas foram desenvolvidas a partir de temas alimentares brasileiros e discutidas em salas de aulas ou no pátio da escola. Cada tema foi trabalhado em dois encontros ou três encontros. Os grupos eram convidados a debater sobre tema que a equipe do projeto levou previamente. Para ilustra essa roda de conversas, abaixo se apresenta alguns desses debates:

4.3.

Debate: o início da culinária brasileira.

Desenvolveu-se um debate em relação à influência da culinária lusitana em nossa cultura, com destaque para a doçaria brasileira. Os doces de amendoim, frutas diversas, castanhas, cocos que durante muito tempo foram preparados de forma artesanal em tachos sobre o fogão à lenha para servir de sobremesa, hoje são produzidos pela indústria alimentícia e consumidos a qualquer hora do dia. Aqui ocorre o que Poulain (2013) chamou de dessocialização da comida na era contemporânea. A comida industrializada não tem alma, história, nem constrói identidades. Essa comida não vem com regras implícitas e nem com códigos sociais. O doce feito na cozinha artesanal tem todo um significado simbólico que representa a cultura aprendida de um povo.

Para resgatar esse aspecto histórico do doce foi mostrado aos estudantes que este alimento só era feito em ocasiões especiais, principalmente, por causa do valor econômico do açúcar. Há evidências que no século XV, já havia uma produção de açúcar que se pagava imposto à Alfândega de Portugal (FREYRE, 2004).

Em outros momentos o doce teve um papel social relevante. A rapadura foi um doce criado a partir da raspagem das camadas de açúcar que ficavam presas às paredes dos tachos utilizados para fabricação de açúcar, então, era aquecido e colocado em fôrmas semelhantes 
às de tijolos. Uma solução prática de transporte de alimento em pequena quantidade para uso individual, que resistia durante meses às mudanças atmosféricas. Chegou ao Brasil em $1532 \mathrm{e}$ serviu como ração para os escravos por possuir muitos nutrientes e ser altamente energético. A rapadura ainda hoje é consumida como alimento base em diversas regiões periféricas do país, onde a industrialização ainda não controlou totalmente as práticas alimentares.

Foi interessante verificar que poucos estudantes conheciam o doce de rapadura que de certa forma carrega junto ele a história e a uma parte da cultura brasileira.

Outro alimento que tem papel importante na culinária brasileira é a farinha de milho, mais especificamente o fubá. O Fubá é uma palavra herdada do código africano para nomear a farinha de milho. No período da colonização, os portugueses foram os maiores responsáveis por uma intensa produção de farinha de milho. A farinha de milho serviu para preparar a papa que também foi uma alimentação típica dos escravos. Os negros resistiam e criavam novas receitas a partir da insossa papa. Associam a farinha de milho, ao açúcar, ovos e leite de coco que em algumas datas específicas (comemorações dos brancos) eram doadas a eles. Com esses ingredientes, faziam da dura e amarga papa diária uma comida saborosa, sedutora que dava esperança de que em breve surgiriam dias mais doces. Tal bolo, ainda hoje, servido à tarde junto com café, no Brasil, representando a tardes amenas. Nesse exemplo simplório resgata-se o passado do Brasil, trazendo movimento e questionamento na engrenagem histórica do brasileiro. (CASCUDO, 1983; FREYRE, 2004)

O básico ato de preparar um bolo, muito comum nas festas juninas, mostra como o povo brasileiro incorpora as receitas e a utiliza para evocar elementos subjetivos. Tais receitas fazem florescer e vivenciar memórias coletivas que buscam espreitar na comida, a rede de teias simbólicas. "A memória é a imaginação no povo, mantida e comunicável pela tradição, movimentando as culturas convergidas para o uso, através do tempo. Essas culturas constituem quase a civilização nos grupos humanos" (CASCUDO, 1983, p.9).

O doce de canjica, também presente nas festas juninas, por exemplo, é outra comida construída pelos escravos negros e foi o alimento mais comum nos quilombos e senzalas, para depois ser difundido por todo o país e adquirir formatações diferentes em cada região, passando a ser considerado um ingrediente típico para diversos pratos brasileiros.

Em suma as discussões surgidas nas oficinas caminharam no sentido de pontuar a importância de não deixar as receitas antigas e suas histórias de origem desaparecer. São as receitas dos nossos antepassados que servem como resistência, na contramão da indústria alimentícia, que criam identidades e nos dão sentidos enquanto povo. 
Aqui os debates caminharam no sentido de mostrar que o Brasil possui rica diversidade cultural no campo das práticas alimentares, entretanto, ao ceder aos apelos da universalização do mundo globalizado fica a mercê do poderio econômico de suas aglomerações empresariais e industriais. Sendo que essas últimas ditam o ritmo de alimentação contemporânea.

Segundo Carreiro (2007), as células do organismo humano necessitam de no mínimo de cerca de quarenta e quatro tipos diferentes nutrientes para sobreviver. Somente uma alimentação base diversificada, tal como era feita antigamente no Brasil, onde se consumia legumes, arroz, feijão, saladas, castanhas, cereais integrais, frutas, tubérculos, farinha de milho, araruta, carnes etc., faria o organismo funcionar de forma adequada. Esse tipo de alimentação não tem espaço na sociedade contemporânea, onde os aglomerados industriais internacionais ditam e mudam os hábitos alimentares dos brasileiros oferecendo à população brasileira alimentos a base de trigo, leite, milho, açúcar e soja.

Como já foi apontado anteriormente, o consumo de alimentos industrializados representa cerca de $85 \%$ do consumo brasileiro contra apenas $15 \%$ dos produtos in natura. Portanto, resgatar a cultura alimentar é combater o domínio da indústria sobre as práticas alimentares da população, fortalecer a alimentação regional e agir em pró da saúde.

\section{5.}

Debate: comida que sustenta tem

\section{história e sabor}

Em um dos debates aprofundou-se no debate e na reafirmação das culinárias tradicionais, provenientes dos encontros étnicos que ocorreram no Brasil, que ajudaram a fundar a identidade brasileira. Dessa forma, a cultura alimentar dos tropeiros, a cozinha mineira e baiana foi retratada como construções sociais de resistência e reafirmação de características culturais étnicas do povo brasileiro. Através da história por trás da escolha, preparo dos alimentos e qualidade nutricional dos mesmos foi discutido com os alunos como as comidas podem mudar o cotidiano dos sujeitos. No caso da comida tropeiro, as receitas feitas a partir de alimentos secos (feijão, carne, farinha de mandioca) proporcionaram longas viagens aos condutores de gado e estimularam a construção de vilas e desenvolvimento do 
comércio brasileiro. A junção entre as práticas alimentares lusitanas (a produção de charque) e a indígenas (produção de farinha de mandioca) são evidentes na cultura dos tropeiros.

A comida baiana retrata uma resistência do povo africano que conseguiu difundir sua cultura através da reconstrução de suas práticas alimentares.

A culinária mineira conseguiu misturar os ingredientes regionais com aqueles que forram trazidos pelos povos africanos e lusitanos e criaram receitas que misturam culturas, tais como o frango com quiabo, a galinha ao molho pardo, pão de queijo, doce de leite, arroz com taioba etc.. Essas cozinhas quando estudadas potencializam a cultura brasileira.

\subsection{Debate: a experiência compartilhada}

Uma idéia surgida através das rodas de conversas e que merecem ser aqui postulada foi à intenção de compartilhar a experiência que surgiam nas oficinas com a comunidade escolar. Os alunos participantes das rodas construírem um espaço de EAN dentro do pátio da escola, cuja finalidade foi oferecer à população da instituição a possibilidade de conhecer a cultura alimentar brasileira. Para isso os alunos fizeram a montagem de um estande temático no pátio da escola: cavalete de tela, mesa com condimentos tipicamente brasileiros, materiais ilustrativos que retratavam a cultura alimentar brasileira etc. Foram oferecidos aos visitantes do espaço materiais produzidos pelo grupo (folders, cartazes, fotos e textos informativos a respeito da cultura alimentar brasileira). Alguns beliscos da cultura alimentar brasileira produzida na oficina de culinária (biscoitos de polvilho, pães de queijo e doces típicos caseiros da culinária nacional, como de doce de batata, pé de moleque, paçoca, manjar, broa de milho etc.) também foram oferecidos a comunidade escolar. A intenção aqui foi atiçar a memória histórica da culinária brasileira e ao mesmo tempo mostrar que o Brasil tem uma rica história na produção de cultura e sabor.

\subsection{Rodas de conversas e práticas reflexivas - o preparo de comidas brasileiras típicas}

A oficina de culinária que também pode ser considerada uma roda de conversas, pois suscitavam debates, teve a intenção de mostrar aos participantes que cozinhar é um ato que reafirma a cultura, é simples, prazeroso e representa a inteligência de um povo. Em todas as atividades feitas na oficina de culinária os participantes foram convidados a cozinhar conjuntamente com os membros da equipe do projeto. Apesar de maioria não participar 
diretamente do preparo dos pratos, observaram atentamente todo o processo que envolve o preparo de uma comida.

Assim, utilizou-se a oficina de culinária no preparo de doces de frutas in natura para indicar que os mesmos podem ser feitos em casa e, que apesar de boa parte desses doces terem muito açúcar em sua composição, são muito menos prejudiciais do que os doces industrializados.

Cabe ressaltar, que não houve nas oficinas uma tentativa de conduzir para uma alimentação disciplinar. Sempre foi informado aos participantes que mesmos os alimentos minimamente processados, como sucos naturais e os doces de compotas, perdem propriedades nutritivas e que podem ser muito calóricos. A vantagem em relação ao preparo dessas comidas é o fortalecimento da cultura alimentar com suas especificidades (comunhão na cozinha, valorização do saber familiar) e a utilização mínima de ingredientes artificiais e aditivos químicos durante sua feitura. Pode-se afirmar essa atividade desenvolveu-se com os grupos um saber culinário que rompeu com a idéia de que, necessariamente, biscoitos e doces só são produzidos em fábricas.

Em outro debate tomou-se o estudo a respeito das frutas, verduras e legumes presentes na região. Receitas que tinham frutas como ingredientes também foram resgatados. Assim, o bolo de banana, a torta de abacaxi, o manjar de coco são exemplos de receitas que foram preparadas durante a oficina. Através do diálogo os estudantes aprenderam que a maior parte das frutas que se consomem atualmente tem limites quanto à variedade e provém originalmente de outros países. Tal fenômeno ocorre, principalmente, pelo fortalecimento do agronegócio, a partir da década de 90, e pela opção dos empresários agrícolas em cultivar frutas que oferecem melhor custo benefício e que podem ser exportadas. O Brasil com essa postura tornou-se um dos maiores exportadores de frutas do mundo. Vale à pena registrar que o mundo universalizado com seus aglomerados industriais e empresariais influi na produção de alimentos e, de certa forma, inibe a produção de alimentos que teriam um apelo apenas regional.

Conhecer novos sabores e texturas de novos alimentos possibilitou aos estudantes uma sensação prazerosa e os instigaram a buscar novas experimentações de alimentos in natura.

Trabalhou-se também com os estudantes a importância de um alimento tipicamente brasileiro e que tem uma importância cultural imensa e que contribui como fonte calórica e nutritiva para que o povo brasileiro povoasse as mais longínquas regiões brasileiras. Trata-se da raiz de mandioca. Uma planta originalmente brasileira que possibilita a produção de diversos produtos (bolos, tapiocas, beijus, biscoitos, doces, bebidas, caldos, pães, farinhas). 
Infelizmente, a desinformação e a produção agrícola pressionada pela universalização da alimentação a base de farináceos de trigo, soja e amido de milho, deixa a produção de mandioca para os pequenos agricultores e, a cada dia, a mesa do brasileiro perde um alimento típico brasileiro. Recentemente, a polêmica em torno dos malefícios do glúten tem reabilitado a mandioca, pois é um alimento que não contém esse elemento e pode substituir de forma palatável os pães e doces feitos a partir de farinhas de trigo. (CARREIRO, 2014). Em suma, produzimos junto com os alunos vários comidas feitas a partir da raiz de mandioca (carne com mandioca cozida, mandioca assada, bolinhos de mandioca) e de suas farinhas (farofa salgada, paçoca de carne, pão de polvilho com queijo etc.).

Os alunos tiveram o prazer e informação compartilhada da relevância que a mandioca tem na cultura brasileira e que consumi-la no lugar de outras fontes de carboidratos mantém a história brasileira viva e atuante.

\section{Conclusões}

A presente proposta contribuiu para a efetivação de uma ação de Educação Alimentar e Nutricional que retomou e aprofundou em elementos históricos, culturais e sociais que permeiam a nutrição e alimentação do brasileiro. Além disso, o debate em torno dos hábitos alimentares adquiridos na contemporaneidade fomentou nos estudantes a busca por uma postura crítica frente à produção de alimentos utraprocessados e as estratégias marqueteiras da indústria alimentícia.

Foi possível mostrar aos alunos as possibilidades de reinventar e experimentar outros sabores, pratos e ingredientes da culinária brasileira que até então eram desconhecidos por muitos deles. Além disso, foi possível resgatar a história da origem dos ingredientes e dos pratos típicos brasileiros, pois cada alimento traz na sua história lutas e tensões entre dominantes e dominados que perduraram por séculos.

Ao resgatar a cultura alimentar brasileira resiste-se à padronização alimentar contemporânea, além de incentivar um consumo de comidas mais saudáveis, uma vez que o preparo dessas se vale de diversos elementos, tais como, a consciência dos ingredientes, o processo de preparo, disponibilidade e nutrientes.

O ato de comer não é apenas alimentar-se, mas entrar em contato com a cultura de um país ou uma região, e de ter consciência em todo o processo de preparo.

A adoção de ações em políticas públicas alimentares gabaritadas pela educação alimentar e nutricional, mesmo aquelas sucintas que agem junto a pequenos grupos, são medidas de enfrentamento às determinações controladoras e operantes das grandes 
corporações alimentares. Percebe-se que um trabalho em EAN é factível de construir um terreno propício para que os sujeitos resistam e reivindique para si um projeto próprio um projeto de alimentação mais cultural e saudável, além da possibilidade de rompimento com a padronização cultural e controladora que assola os processos alimentares brasileiros na contemporaneidade.

\section{Referências}

ALVES, K. P. S; JAIME, P.C. A Política Nacional de alimentação e Nutrição e seu diálogo com a Política Nacional de Segurança alimentar e Nutricional. Ciênc. Saúde coletiva. vol.19 n.11 Rio de Janeiro Nov. 2014

BARBOSA DA SILVA, A.C. Culturas e práticas alimentares em questão: psicologia e educação. Marília: Poiesis Editora, 2016.

BELICK, W.; SILVA, J. G. da; TAKAGI, M. Políticas de combate à fome no Brasil. São Paulo Perspectiva, São Paulo, v. 15, n. 4, p. 119-129, Dec. 2001.

BIANCO, A. L.; CASSIANO, A. C. R. L. de. Superalimentados, mas subnutridos: um diagnóstico do sistema alimentar industrial. Ambiente e Sociedade, Campinas, v. 12, n. 1, p. 203-206, 2009.

BRASIL. Ministério da Saúde. Secretaria de Políticas de Saúde. Política Nacional de Alimentação e Nutrição. Brasília: Ministério da Saúde; 1999.

BRASIL. Ministério da Saúde. Secretaria de Políticas de Saúde. Coordenação-Geral da Política de Alimentação e Nutrição. Alimentos regionais brasileiros. Brasília: Ministério da Saúde; 2002.

BRASIL. Ministério da Saúde. Marco de Referência de Educação Alimentar e Nutricional para as Políticas Públicas. Brasília: Ministério da Saúde; 2003.

BRASIL. Ministério da Saúde. Coordenação-Geral da Política de Alimentação e Nutrição. Análise dos Registros do Consumo Alimentar. Boletim SISVAN n 10. Brasília: Ministério da Saúde; 2009.

BRASIL. Ministério da Saúde. Secretaria de Atenção à Saúde. Departamento de Atenção Básica. Política Nacional de Alimentação e Nutrição. Brasília: Ministério da Saúde; 2013.

BOOG, M. C. F. Educação nutricional: passado, presente, futuro. Revista de Nutrição, Campinas, v.10, n.1, p. 5-19, 1997.

CASCUDO, C. História da Alimentação Brasileira. Belo Horizonte: Itatiaia, 1983.

CARREIRO, D.M. Entendo a importância do processo alimentar. São Paulo: Edição do Autor, 2007 
COSTA, J. F. Quatro autores em busca do Brasil. Rio de Janeiro: Rocco, 2000.

DÓRIA, C. A. A cozinha subdesenvolvida. Trópico: ideias de Norte a Sul. Uol. São Paulo, 23 mar. 2002. Disponível em: http:// www.uol.com.br/tropico/. Acesso em: 05/03/2015.

FREYRE, G. Casagrande \& Senzala: formação da família brasileira sob o regime da economia patriarcal. 49. ed. São Paulo: Global, 2004.

GARCIA, R. W. D. Reflexos da globalização na cultura alimentar: considerações sobre as mudanças na alimentação urbana. Revista de Nutrição, Campinas, v. 16, n. 4, p. 483-492, 2003.

INSTITUTO BRASILEIRO DE GEOGRAFIA E ESTATÍSTICA - IBGE. Pesquisa Industrial Anual 2014.

POLLAN, M. Cozinhar: uma história natural da transformação. Rio de Janeiro: Intríseca, 2014.

POULAIN JP. Sociologias da alimentação: os comedores e o espaço social alimentar. Florianópolis: UFSC, 2013.

RODRIGUES, V. M.; FIATES, G. M. R. Hábitos alimentares e comportamento de consumo infantil: influência da renda familiar e do hábito de assistir à televisão, Revista de nutrição. Campinas, v. 25, n. 3, p. 353-362, 2012.

SILVA, A. C. B. ET al. Educação alimentar e nutricional, cultura e subjetividades: a escola contribuindo para a formação de sujeitos críticos e criativos em torno da cultura alimentar. DEMETRA: Alimentação, Nutrição \& Saúde, v. 10, n. 2, p. 247-257, 2015.

VALENTE, F. L. Direito Humano à Alimentação: desafios e conquistas. São Paulo: Editora Cortez; 2002. 